\title{
Genetic association of HCRTR2, ADH4 and CLOCK genes with cluster headache: a Chinese population-based case-control study
}

Zhiliang Fan ${ }^{1,2}$, Lei Hou', Dongjun Wan ${ }^{1}$, Ran Ao ${ }^{1}$, Dengfa Zhao ${ }^{1}$ and Shengyuan Yu ${ }^{1 *}$ (D)

\begin{abstract}
Background: Cluster headache $(\mathrm{CH})$, a rare primary headache disorder, is currently thought to be a genetic susceptibility which play a role in $\mathrm{CH}$ susceptibility. A large numbers of genetic association studies have confirmed that the HCRTR2 (Hypocretin Receptor 2) SNP rs2653349, and the ADH4 (Alcohol Dehydrogenase 4) SNP rs1126671 and rs1800759 polymorphisms are linked to CH. In addition, the CLOCK (Circadian Locomotor Output Cycles Kaput) gene is becoming a research hotspot for $\mathrm{CH}$ due to encoding a transcription factor that serves as a basic driving force for circadian rhythm in humans. The purpose of this study was to evaluate the association between $\mathrm{CH}$ and the HCRTR2, ADH4 and CLOCK genes in a Chinese CH case-control sample.
\end{abstract}

Methods: We genotyped polymorphisms of nine single nucleotide polymorphisms (SNPs) in the HCRTR2, ADH4 and CLOCK genes to perform an association study on a Chinese Han CH case-control sample (112 patients and 192 controls) ,using Sequenom MALDI-TOF mass spectrometry iPLEX platform. The frequencies and distributions of genotypes and haplotypes were statistically compared between the case and control groups to identify associations with $\mathrm{CH}$. The effects of SNPs on CH were further investigated by multiple logistic regression.

Results: The frequency of the HCRTR2 SNP rs3800539 GA genotype was significantly higher in cases than in controls (48.2\% vs.37.0\%). The GA genotypes was associated with a higher $\mathrm{CH}$ risk $(\mathrm{OR}=1.483,95 \% \mathrm{Cl}: 0.564-3.387, p=0.038)$, however, after Bonferroni correction, the association lost statistical significance. Haplotype analysis of the HCRTR2 SNPS showed that among eight haplotypes, only H1-GTGGGG was linked to a reduced $\mathrm{CH}$ risk (44.7\% vs. 53.1\%, OR=0.689, $95 \% \mathrm{Cl}=0.491 \sim 0.966, p=0.030$ ). No significant association of ADH4, CLOCK SNPs with CH was statistically detected in the present study.

Conclusions: Association between HCRTR2, ADH4,CLOCK gene polymorphisms and $\mathrm{CH}$ was not significant in the present study, however, haplotype analysis indicated H1-GTGGGG was linked to a reduced $\mathrm{CH}$ risk.

Keywords: Cluster headache, Gene polymorphism, HCRTR2, ADH4, Clock

\footnotetext{
*Correspondence: yusy1963@126.com

'Department of Neurology, Chinese People's Liberation Army General

Hospital, Fuxing Road 28, Haidian District, Beijing 100853, China

Full list of author information is available at the end of the article
} 


\section{Background}

Cluster headache $(\mathrm{CH})$ is a relatively rare, severe type of primary trigeminal autonomic cephalalgia [1]. It has clinically unique features of excruciating unilateral periorbital pain with recurrent short-lasting attacks (15 to $180 \mathrm{~min}$ ), accompanied by cranial autonomic symptoms, such as nasal congestion, runny nose (rhinorrhea), tears and eye congestion. According to the cluster period or the duration of remission, $\mathrm{CH}$ can be divided into episodic and chronic [2].

The etiology and pathogenic mechanism of cluster headache has been not clarified absolutely, however, recent research has shown that genetic and environmental factors have potential relations with $\mathrm{CH}$ [3]. Currently, about $5 \%-20 \%$ of $\mathrm{CH}$ patients had $\mathrm{CH}$ family history. Familial occurrence of $\mathrm{CH}$ has been presented at least four studies, compared with the general population, the risk of direct lineal descendants increased by 14 to 39 times, while the risk of branch lineal descendants increased by 2 to 8 times [4-7]. $\mathrm{CH}$ in monozygotic twins were also observed to be suffered from paroxysmal tachycardia [8-10]. Russell et al. (1995) revealed that autosomal dominant genes play a significant role in $\mathrm{CH}$ in some families [11]. Therefore, $\mathrm{CH}$ is believed to be a genetic susceptibility disease, but at present, the type and the number of genes involved are still unclear.

Previous study hypothesized that the pathogenesis of $\mathrm{CH}$ is associated with the changes of circadian rhythm and neuroendocrine disorders in the hypothalamus [12]. The hypothalamus gastrin-releasing peptides (hypocretin, HCRTs) are neuropeptides, which are synthesized by neurons located in the hypothalamus lateral area to regulate arousal, wakefulness and appetite. It is observed that there is a connection between these peptides and nociceptive phenomena in $\mathrm{CH}$. A possible explanation for this mechanism is that HCRTS binds to G-protein coupled receptors (GPCRs), including HCRTR1 and $H C R T R 2$, to regulate various physiological responses such as sleep awakening, dietary energy metabolism and blood pressure [13, 14]. Four studies revealed significant association of HCTR gene polymorphism with $\mathrm{CH}$. A significant association between a $1246 \mathrm{G}-\mathrm{A}$ polymorphism ( $\mathrm{rs} 2653349$ ) in the HCRTR2 gene and $\mathrm{CH}$ has been independently reported by two research groups [15-18].

About $52 \%-79 \%$ of $\mathrm{CH}$ occur during the onset of the disease while alcohol can trigger an episode during a cluster period [19]. Alcohol is metabolizatied by alcohol dehydrogenase (ADH), which is a group of dehydrogenase enzymes mainly distributed in the liver and gastrointestinal tract [20]. Ethanol dehydrogenase 4 (ADH4), encoded by the $A D H 4$ gene, is a member of the $\mathrm{ADH}$ family, and associated with many diseases including Parkinson's disease, alcohol and drug-dependent syndromes $[21,22]$. Alcohol is a well-known trigger factor for $\mathrm{CH}$ attacks during the active phases of the disease. Three studies have been made,two Italian groups revealed significant association of the rs1126671 locus in the ADH4 gene with $\mathrm{CH}$ incidence,one of the experiments have also found the association between the ADH4 SNP rs1800759 and $\mathrm{CH}$,but those results were not confirmed in a large Swedish case-control cohort study [23-25].

$\mathrm{CH}$ is characterized by periodic series of episodes. Therefore, the abnormal internal CLOCK function of hypothalamus is hypothesized to associate with $\mathrm{CH}$ pathophysiology. CLOCK (Circadian Locomotor Output Cycles Kaput) gene, as a candidate gene for $\mathrm{CH}$, which encodes a protein belonging to the superfamily of the basic helix-loop-helix-PAS transcription factor, affects the persistence and the period of circadian rhythm in humans [26]. Recently,four studies have been conducted to investigate the association of the polymorphism of the human CLOCK gene (rs1801260) with $\mathrm{CH}$,however, no consistent evidence for association of CLOCK with $\mathrm{CH}$ was observed yet [24, 27-29].

The identification of association of genes with $\mathrm{CH}$ seems to be a difficult task. To date, there is a limited number of the research on genetic association of polymorphisms in the HCRTR2, ADH4 and CLOCK genes with $\mathrm{CH}$ with contradictory results. Knowledge and understanding of genes for $\mathrm{CH}$ derive primarily from studies in Western populations. The molecular association profile of $\mathrm{CH}$ in Asia, particularly in Chinese patients have not been fully studied. The purpose of this study was to evaluate the association between $\mathrm{CH}$ and the HCRTR2 (rs10498801, rs2653342,rs2653349, rs3122156, rs3800539, rs9357855), $A D H 4($ rs1126671、rs1800759) and CLOCK (rs1801260) genes, estimating the frequency of different gene haplotypes in a Chinese case-control cohort population. Our study provided abundant information and reference value for genes involved with $\mathrm{CH}$ in Chinese Han population.

\section{Methods \\ Study samples}

A total of $112 \mathrm{CH}$ patients (100 men and 12 women) were recruited by neurologists in the International Headache Center of the Department of Neurology of the Chinese PLA General Hospital between September 2014 and October 2017. The mean age of the patients is 35.43 years, with a standard deviation of 10.56 years. The $\mathrm{CH}$ was diagnosed according to the International Classification of Headache Disorders (ICHD-III beta). The candidates in the control group were matched with the candidates in the case group by age and gender, and recruited from physical examination center of the same geographic areas, consisting of 192 unrelated nonheadache healthy volunteers (170 men and 22 women). The mean age of the healthy volunteers is 35.81 years, 
with a standard deviation of 10.87 years. All candidates ( $\mathrm{CH}$ and controls) with stroke, tumors or a history of mental disease were excluded. Both $\mathrm{CH}$ patients and controls were from the Chinese Han population according to the selection criteria as follows: 1) registered as the ethic Han, 2) their parents were registered as the ethnic Han, and 3) the families have settled in China for more than 5 generations without marrying other ethics and intermarrying with other nationalities. The clinical profiles and characteristics of both $\mathrm{CH}$ patients and controls in the study is showed in Table 1.

\section{DNA isolation and genotyping}

A $200 \mathrm{~mL}$ of peripheral blood was collected from each of patients and controls. Genomic DNA was extracted from the lymphocytes present in $200 \mathrm{~mL}$ peripheral blood using the TIANamp Blood DNA Kit (Tian-gen Biotech, Beijing, China), according to standard manufacturer's protocols. The primers are designed by Agena Bioscience ADS2.0 software (http://agenabio.com/), and synthesized by Beijing LiuheHuada Gene Technology Co., Ltd. (Beijing, China). The sequences of the primers are listed in the Additional file 1: Table S1.

The multiple PCR genotyping is conducted in GeneAmp - PCR System 9700 Dual 384-Well Sample Block Module according to the manufacturer's instruction (Agena Bioscience, USA). PCR products were purified to remove salts by cation-exchange resin. The chip was prepared by using microarray Nanodispenser (MassARRAY Nanodispenser) on the SpectroCHIP microarray (SpectroCHIP). Single nucleotide polymorphism (SNP) genotyping was performed

Table 1 Clinical characteristics of the study population

\begin{tabular}{llll}
\hline & $\mathrm{CH}(n=112)$ & $\begin{array}{l}\text { Control } \\
(n=192)\end{array}$ & $P$ value \\
\hline Age (mean \pm SD) & $35.43 \pm 10.56$ & $35.81 \pm 10.87$ & 0.398 \\
Sex (M/F) & $100 / 12$ & $170 / 22$ & 0.959 \\
Age at onset (years) & $25.53 \pm 9.28$ & & \\
Headache duration & & & \\
$<1 \mathrm{~h}$ & 43 & & \\
$1 \mathrm{~h}-2 \mathrm{~h}$ & 43 & & \\
2 h-3 h & 26 & & \\
Type of attack & & & \\
$\quad$ Episodic type & 99 & \\
Chronic type & 13 & \\
Drinking induced & & \\
yes & 22 & \\
no & 90 & \\
Family history of Cluster headache & \\
yes & 9 & \\
no & 103 & \\
\hline
\end{tabular}

by using MassARRAY Analyzer 4 System (http://agenabio.$\mathrm{com} /$ products/massarray-system/). The quality and classification of SNP data were evaluated by using RT MassARRAY ${ }^{\mathrm{m}}$ software. SpectroREAD software (Squenom, Inc. San Diego, USA) was used for automatically data collection and processing, subsequently, analysis and load into database by comparing with the theoretical value. Typer 4.0 software (Sequenom, Inc. San Diego, USA) (NASDAQ: SQNM) was used to analyze the original testing data of the test project to normalize the testing results.

\section{Statistical analysis}

The basic characteristics of the case and control groups were measured by t-test or chi-square test. The HardyWeinberg equilibrium was verified for all subjects. The distribution of SNPs (genotypes and alleles) of the three genes was compared with the chi-square test, and the odds ratios (OR) with 95\% confidence intervals (CI) was estimated. The significant level was corrected during multiple comparisons by the Bonferroni correction, and a $p$ value $<0.05 /$ number of comparisons was considered statistically significant. SHEsis was used to construct the single body of 6 SNPs in the HCRTR2 gene and compare the distribution differences between the control and the case groups. Multivariate logistic regression was used to analyze the effects of SNPs and related factors on $\mathrm{CH}$ for detection of the ultimate risk factors and calculation of the OR and 95\% CI. $P<0.05$ was considered significant.

\section{Results}

\section{Clinical characteristics of the case-control study population}

The study population consisted of 112 patients (100 males and 12 females) and 192 controls (170 males and 22 females). The mean age of the cases was $35.43 \pm$ 10.56 years, while the mean age of the 192 controls was $35.81 \pm 10.87$ years. T-test showed no significant differences in age and gender between the case and control groups ( $p=0.398 / p=0.959$, respectively) (Table 1$)$.

\section{Genotype and allele frequency of the polymorphisms between the cases and controls genotype and allelic analysis}

All the genes showed the polymorphisms of SNPs except for rs1126671 that was excluded from the statistical analysis. The allele frequency at each locus and the genotype distributions of all SNPs were in the HardyWeinberg equilibrium in both patients and controls $(P>$ $0.05)$. The genotype and allele frequencies of all 8 SNPs in cases and controls are shown in Table 2. The frequency of the rs 3800539 GA genotypes was significantly higher in cases than in controls $(48.2 \%$ vs.37.0\%). The $\mathrm{GA}$ genotypes was associated with a higher $\mathrm{CH}$ risk 
Table 2 Genotype and allele frequency of the polymorphisms between cases and controls

\begin{tabular}{|c|c|c|c|c|c|c|c|}
\hline \multicolumn{2}{|l|}{$\overline{S N P}$} & \multirow[t]{2}{*}{$\begin{array}{l}\mathrm{CH} \\
(\mathrm{n}=112)\end{array}$} & \multirow[t]{2}{*}{$\begin{array}{l}\text { Controls } \\
(\mathrm{n}=192) \\
\end{array}$} & \multirow{2}{*}{$\begin{array}{l}p \text {-value } \\
\text { HCRTR2 }\end{array}$} & \multirow[t]{2}{*}{$p^{\text {corr }}$} & \multirow[t]{2}{*}{ Crude OR (95\% Cl) } & \multirow[t]{2}{*}{ Adjusted OR ${ }^{\mathrm{a}}(95 \% \mathrm{Cl})$} \\
\hline & & & & & & & \\
\hline \multirow[t]{3}{*}{ rs10498801(G > A) } & GG & $53(0.473)$ & $95(0.495)$ & & & 1 & 1 \\
\hline & GA & $46(0.411)$ & $83(0.432)$ & 0.979 & 1 & $1.003(0.798-1.261)$ & $1.014(0.596-1.631)$ \\
\hline & AA & 13(0.116) & $14(0.073)$ & 0.224 & 0.672 & $1.664(0.728-3.803)$ & $1.634(0.863-4.125)$ \\
\hline HWE $p$-value & & 0.536 & 0.473 & & & & \\
\hline \multirow[t]{2}{*}{ Allele } & G & 152(0.679) & $273(0.711)$ & & & 1 & - \\
\hline & A & $72(0.321)$ & $111(0.289)$ & 0.599 & & $1.110(0.771-1.568)$ & - \\
\hline \multirow[t]{3}{*}{$\operatorname{rs} 2653342(A>G)$} & GG & $100(0.893)$ & 175(0.911) & & & 1 & 1 \\
\hline & $\mathrm{GA}$ & $11(0.098)$ & $17(0.089)$ & 0.760 & 1 & $1.132(0.510-2.513)$ & $1.141(0.519-2.404)$ \\
\hline & $\mathrm{AA}$ & $1(0.009)$ & $0(0.000)$ & 0.281 & 0.843 & $3.485(0.312-38.91)$ & - \\
\hline HWE $p$-value & & 0.281 & 0.521 & & & & \\
\hline \multirow[t]{2}{*}{ Allele } & G & $211(0.942)$ & $367(0.956)$ & & & 1 & - \\
\hline & A & 13(0.058) & $17(0.044)$ & 0.454 & & $1.330(0.634-2.793)$ & - \\
\hline \multirow[t]{3}{*}{ rs2653349(G > A) } & GG & $98(0.875)$ & $176(0.917)$ & & & 1 & 1 \\
\hline & GA & 13(0.116) & $16(0.083)$ & 0.336 & 1 & $1.459(0.674-3.159)$ & $1.536(0.709-3.331)$ \\
\hline & $\mathrm{AA}$ & $1(0.009)$ & $0(0.000)$ & 0.268 & 0.804 & $0.989(0.969-1.010)$ & - \\
\hline HWE $p$-value & & 0.452 & 0.546 & & & & \\
\hline \multirow[t]{2}{*}{ Allele } & G & 209(0.933) & $368(0.958)$ & & & 1 & - \\
\hline & A & $15(0.067)$ & $16(0.042)$ & 0.171 & & $1.651(0.800-3.407)$ & - \\
\hline \multirow[t]{3}{*}{ rs3122156(T > G) } & $\pi$ & $56(0.500)$ & $106(0.552)$ & & & 1 & 1 \\
\hline & GT & $47(0.420)$ & $74(0.385)$ & 0.460 & 1 & $1.202(0.738-1.959)$ & $1.127(0.427-2.974)$ \\
\hline & GG & $9(0.080)$ & $12(0.063)$ & 0.455 & 1 & $1.420(0.564-3.573)$ & $1.314(0.507-3.410)$ \\
\hline HWE $p$-value & & 0.843 & 0.847 & & & & \\
\hline \multirow[t]{2}{*}{ Allele } & G & 159(0.710) & $286(0.745)$ & & & 1 & - \\
\hline & $\mathrm{T}$ & $65(0.290)$ & $98(0.255)$ & 0.348 & & $1.193(0.825-1.725)$ & - \\
\hline \multirow[t]{3}{*}{ rs3800539(G > A) } & GG & $48(0.429)$ & 106(0.552) & & & 1 & 1 \\
\hline & GA & $54(0.482)$ & $71(0.370)$ & 0.038 & 0.114 & $1.680(1.027-2.746)$ & $1.483(0.564-3.387)$ \\
\hline & $\mathrm{AA}$ & $10(0.089)$ & 15(0.078) & 0.382 & 1 & $1.472(0.617-3.513)$ & $0.835(0.339-2.057)$ \\
\hline HWE $p$-value & & 0.342 & 0.522 & & & & \\
\hline \multirow[t]{2}{*}{ Allele } & G & $150(0.670)$ & $283(0.737)$ & & & 1 & - \\
\hline & A & $74(0.330)$ & $101(0.263)$ & 0.707 & & $1.382(0.965-1.980)$ & - \\
\hline \multirow[t]{3}{*}{ rs9357855(G > A) } & GG & $65(0.580)$ & $124(0.646)$ & & & 1 & 1 \\
\hline & GA & $41(0.366)$ & $61(0.318)$ & 0.326 & 0.978 & $1.282(0.780-2.107)$ & $1.423(0.444-4.565)$ \\
\hline & $\mathrm{AA}$ & $6(0.054)$ & $7(0.036)$ & 0.390 & 1 & $1.635(0.528-5.067)$ & $1.694(0.546-5.257)$ \\
\hline HWE $p$-value & & 0.887 & 0.881 & & & & \\
\hline \multirow[t]{2}{*}{ Allele } & G & $171(0.763)$ & $309(0.805)$ & & & 1 & - \\
\hline & $A$ & $53(0.237)$ & $75(0.195)$ & 0.228 & & $1.277(0.857-1.902)$ & - \\
\hline & & & & $\mathrm{ADH} 4$ & & & \\
\hline \multirow[t]{3}{*}{$\mathrm{rs} 1800759(\mathrm{G}>\mathrm{T})$} & GG & $77(0.688)$ & $130(0.677)$ & & & 1 & 1 \\
\hline & GT & $33(0.295)$ & $54(0.281)$ & 0.906 & 1 & $1.032(0.615-1.730)$ & $1.132(0.524-2.441)$ \\
\hline & $\pi$ & $2(0.017)$ & $8(0.042)$ & 0.270 & 0.810 & $0.422(0.087-2.039)$ & $0.464(0.096-2.251)$ \\
\hline HWE $p$-value & & 0.469 & 0.432 & & & & \\
\hline
\end{tabular}


Table 2 Genotype and allele frequency of the polymorphisms between cases and controls (Continued)

\begin{tabular}{|c|c|c|c|c|c|c|c|}
\hline$\overline{S N P}$ & & $\begin{array}{l}\mathrm{CH} \\
(\mathrm{n}=112)\end{array}$ & $\begin{array}{l}\text { Controls } \\
(n=192)\end{array}$ & $p$-value & $p^{\text {corr }}$ & Crude OR (95\% Cl) & Adjusted OR ${ }^{\mathrm{a}}(95 \% \mathrm{Cl})$ \\
\hline \multirow[t]{3}{*}{ Allele } & G & $187(0.835)$ & $314(0.818)$ & & & 1 & - \\
\hline & T & $37(0.165)$ & $70(0.182)$ & 0.593 & & $0.888(0.573-1.375)$ & - \\
\hline & & & & CLOCK & & & \\
\hline \multirow[t]{3}{*}{$\mathrm{rs} 1801260(T>C)$} & AA & $92(0.821)$ & $167(0.870)$ & & & 1 & 1 \\
\hline & $A G$ & 19(0.170) & $23(0.120)$ & 0.226 & 0.678 & $1.500(0.776-2.898)$ & $1.471(0.766-2.823)$ \\
\hline & GG & $1(0.009)$ & $2(0.010)$ & 0.937 & 1 & $0.908(0.081-10.145)$ & $1.151(0.533-3.487)$ \\
\hline HWE $p$-value & & 0.986 & 0.245 & & & & \\
\hline \multirow[t]{2}{*}{ Allele } & A & 203(0.906) & $357(0.930)$ & & & 1 & - \\
\hline & G & $21(0.094)$ & $27(0.070)$ & 0.301 & & $1.368(0.754-2.482)$ & - \\
\hline
\end{tabular}

a: Adjusted for age, sex by logistic regression

$p^{\text {corr }}: p$ value is adjusted by Bonferroni correction

$(\mathrm{OR}=1.483,95 \% \mathrm{CI}:$ 0.564-3.387, $p=0.038)$, However, there was no signifcant association after the correction for multiple tests $\left(p^{\text {corr }}=0.114\right)$. There was no significant difference in the distributions of genotypes and alleles of other SNPs between patients and controls (Table 2).

\section{Haplotype analysis of the HCRTR2 SNPs}

Haplotypes were constructed for cases and controls, and eight major haplotypes with frequency more than 3\% were identified (Table 3). Among eight haplotypes, only H1-GTGGGG showed significant difference (44.7\% vs. $53.1 \%, \quad \mathrm{OR}=0.689, \quad 95 \% \mathrm{CI}=0.491 \sim 0.966, p=0.030)$, while the other haplotypes $(\mathrm{H} 2, \mathrm{H} 3, \mathrm{H} 4, \mathrm{H} 5, \mathrm{H} 6, \mathrm{H} 7$ and $\mathrm{H} 8$ ) had no significant difference between the cases and controls (Table 3).

\section{Multiple logistic regression}

Nine variants (rs10498801, rs2653342, rs2653349, rs3122156, rs3800539, rs9357855, rs1800759, rs1801260 and gender) were included in the multivariate analysis (stepwise backward LR), from which two variants (rs3800539 and rs1801260) were included in the final multiple regression analysis. As shown in Table 4, no significant difference was detected in the distributions of seven SNPs between patients and controls, after adjusting by multiple logistic regression analysis.

\section{Discussion}

As far as we are aware, the present study is the first to explore molecular evidence for association of different genotypes of SNPs in HCRTR2, ADH4 and CLOCK genes with $\mathrm{CH}$ in Chinese Han population. The molecular genetic profiles of $\mathrm{CH}$ are mainly derived from the Western populations. Rainero et al. (2004) studied polymorphisms of the HCRTR1 and HCRTR2 genes, and revealed obvious difference for the polymorphisms of the HCRTR2 rs2653349 loci between case and control groups. Compared with GA/AA genotype carriers, homozygous carriers of the HCRTR2 1246 GG genotype had the 5-fold increased $\mathrm{CH}$ risk $(\mathrm{OR}=5.06,95 \% \mathrm{CI}=$ 1.99-13.64, $P=0.0002$ ) [16]. Schurks et al. (2006) repeated the study with 226 cases of $\mathrm{CH}$ patients in Germany, conforming the 2-fold increased risk of carriers with homozygous $G$ allele [17]. However, no statistically significant association of the polymorphism of HCRTR2 rs2653349 with $\mathrm{CH}$ was found in several case-

Table 3 Haplotype analysis of the HCRTR2 SNPs between cases and controls

\begin{tabular}{lllll}
\hline Haplotypes $^{\text {a }}$ & Case frequency & Control frequency & $p$-value & OR (95\% Cl) \\
\hline H1-GTGGGG & $100.11(0.447)$ & $203.74(0.531)$ & 0.030 & $0.689[0.491 \sim 0.966]$ \\
H2-GTGGAG & $26.31(0.117)$ & $29.18(0.076)$ & 0.094 & $1.602[0.919 \sim 2.794]$ \\
H3-AGGAAG & $25.17(0.112)$ & $32.34(0.084)$ & 0.270 & $1.284[0.728 \sim 2.264]$ \\
H4-AGGGGG & $14.91(0.067)$ & $18.71(0.049)$ & 0.369 & $1.378[0.683 \sim 2.781]$ \\
H5-GGGAGG & $8.55(0.038)$ & $17.19(0.045)$ & 0.678 & $0.838[0.362 \sim 1.936]$ \\
H6-GTAGGA & $11.05(0.049)$ & $11.89(0.031)$ & 0.262 & $1.608[0.696 \sim 3.713]$ \\
H7-ATGGGG & $6.39(0.029)$ & $18.79(0.049)$ & 0.213 & $0.564[0.226 \sim 1.406]$ \\
H8-ATGGAG & $8.06(0.036)$ & $12.68(0.033)$ & 0.866 & $1.081[0.439 \sim 2.657]$ \\
\hline
\end{tabular}

a Haplotypes were omitted if the estimated haplotype probability was less than 3\%. Order of polymorphisms: rs10498801-rs3122156-rs9357855-rs2653342-rs3800539rs2653349.Global $X 2$ is $9.928, d f=8, p=0.277$ 
Table 4 Multiple logistic regression of the relation between the 8 polymorphisms and $\mathrm{CH}$

\begin{tabular}{|c|c|c|c|c|}
\hline SNP & Estimate & Wald & $p$-value & $\begin{array}{l}\text { Point estimate OR } \\
(95 \% \mathrm{Cl})\end{array}$ \\
\hline $\begin{array}{l}\text { rs3800539 } \\
\text { (GG Vs. GA + AA) }\end{array}$ & 0.417 & 0.813 & 0.063 & $1.513(0.654 \sim 3.912)$ \\
\hline $\begin{array}{l}\text { rs10499801 } \\
\text { (GG Vs. GA + AA) }\end{array}$ & 0.351 & 0.409 & 0.653 & $1.481(0.495 \sim 4.354)$ \\
\hline $\begin{array}{l}\text { rs3122156 } \\
\text { (TT Vs. TG + GG) }\end{array}$ & 0.076 & 0.038 & 0.824 & $1.125(0.554 \sim 2.186)$ \\
\hline $\begin{array}{l}\text { rs9357855 } \\
\text { (GG Vs. GA + AA) }\end{array}$ & 0.186 & 1.210 & 0.845 & $1.325(0.248 \sim 3.712)$ \\
\hline $\begin{array}{l}\text { rs1800759 } \\
\text { (GG Vs. GT + TT) }\end{array}$ & -0.015 & 0.018 & 0.913 & $0.986(0.635 \sim 1.531)$ \\
\hline $\begin{array}{l}\text { rs1801260 } \\
\text { (CC Vs. CT + TT) }\end{array}$ & -0.682 & 0.432 & 0.362 & $1.482(0.539 \sim 2.984)$ \\
\hline $\begin{array}{l}\text { rs } 2653342 \\
\text { (GG Vs. GA + AA) }\end{array}$ & 0.192 & 0.181 & 0.963 & 1. $231(0.423 \sim 3.325)$ \\
\hline $\begin{array}{l}\text { rs2653349 } \\
\text { (GG Vs. GA + AA) }\end{array}$ & 0.293 & 0.456 & 0.993 & $1.382(0.615 \sim 3.464)$ \\
\hline $\begin{array}{l}\text { Sex } \\
\text { (male Vs. female) }\end{array}$ & 0.187 & 0.154 & 0.868 & $1.236(0.572 \sim 36.491)$ \\
\hline
\end{tabular}

control studies in Denmark, Sweden and the UK populations. One reason may be due to the small sample size in these studies, genetic background and environmental exposures [18]. Weller et al. (2015) genotyped a large sample of Dutch $\mathrm{CH}$ patients (575) and controls (874), and confirmed positive association of HCRTR2 rs2653349 polymorphism with $\mathrm{CH}$ incidence by metaanalysis [15]. In the present study, no statistically significant correlation was found between HCRTR2 rs2653349 and $\mathrm{CH}$ in a Chinese Han population consisting of 112 $\mathrm{CH}$ patients and 192 controls. Interestingly, we found that the frequency of the rs3800539 GA genotypes was significantly higher in cases than in controls $(48.2 \%$ vs.37.0\%). Moreover, the GA genotypes was detected to associate with a higher $\mathrm{CH}$ risk $(\mathrm{OR}=1.483,95 \% \mathrm{CI}$ : 0.564-3.387, $p=0.038$ ), however, no significant was found after Bonferroni multiple correction. Under the circumstances, the possible explanation is that small sample size could decrease statistical power. Furthermore, we would need a larger sample size to validate differences. Haplotype analysis of the HCRTR2 SNPs revealed that only H1-GTGGGG had significant lower frequency in cases than in controls $(44.7 \%$ vs. $53.1 \%$, OR $=0.689,95 \% \mathrm{CI}=0.491 \sim 0.966, p=0.030$ ). The further study in the HCRTR2 gene should focus on effects of haploid factors on $\mathrm{CH}$.

$A D H 4$ gene, encoding an enzyme that plays an important role in the metabolism of alcohol, is an interesting candidate gene for $\mathrm{CH}$. To date, there is little consistent evidence for the association of $A D H 4$ SNPs rs1126671 and rs1800759 with $\mathrm{CH}$. Eising et al. (2017) revealed no association of $A D H 4$ with previously reported pathogenic mechanisms [30]. Previous studies reported contradictive results, which were dependent on variance in genotype, allele, and haplotype frequencies among the different populations. Rainero et al. (2010) found that the rs1126671 located in exon 7 of the $A D H 4$ gene was associated with an increased risk for $\mathrm{CH}$ in Italian case-control study, and the carriers with homozygous rs1126671 AA genotype had more than 2-fold $\mathrm{CH}$ risk than those with GG/GA genotypes $(\mathrm{OR}=2.33,95 \% \mathrm{CI}=1.254 .37, P=0.006)$ [23]. In addition, Zarrilli et al. (2015) also found an association between the ADH4 SNP rs1800759 and CH [24]. However, the association was not supported by the case control study of Fourier et al. (2016), who reported no association of the ADH4 SNPs rs1126671 and rs1800759 with $\mathrm{CH}$ using a largest Sweden population [25]. Similarly, the data of our study did not support an association of the $A D H 4$ SNPs rs1126671 and rs1800759 with $\mathrm{CH}$. Interestingly, the present study confirmed that rs1126671 is not polymorphic in the Chinese Han population. This result is consistent with the results of PUBMED SNP library. The possible explanation for these results are as follows: Chinese patients have some different clinical profiles of $\mathrm{CH}$ from the Western ones, showing a relatively low prevalence of chronic $\mathrm{CH}$, pain sites mainly focused on areas distributed by the first division of the trigeminal nerve, a low frequency of restlessness and absent aura. Therefore, ADH4 rs1126671 could not be considered as a biomarker for screening $\mathrm{CH}$ in Chinese case-control group.

The present study did not provide supportive evidence for significant association of CLOCK gene rs 1801260 with $\mathrm{CH}$ in Chinese Han population. A large part of these studies have proved this result, for instance, Rainero et al. (2005) reported that there was no correlation between the CLOCK gene $3092 \mathrm{~T}->\mathrm{C}(\mathrm{rs} 1801260)$ and $\mathrm{CH}$ in an Italian $\mathrm{CH}$ case-control sample (210 patients and 107 controls) [27], which is supported by subsequent studies of Zarrilli et al. (2015) and Cevoli et al. (2008) [24, 28]. Recently, Fourier et al. (2017) found a significant association of CLOCK gene rs12649507 with $\mathrm{CH}(p=0.0069, \mathrm{OR}=1.29,95 \% \mathrm{CI}=1.08 \sim 1.54)$ in a large Swedish CH case-control sample (449 patients and 677 controls) [29], strengthening the hypothesis of the involvement of circadian rhythm in $\mathrm{CH}$. No significant association of CLOCK rs1801260 with $\mathrm{CH}$ was statistically detected in the present study, consistent with the previous results. Although a significant association with $\mathrm{CH}$ in Chinese case-control group was not found, $C L O C K$ as a candidate gene for screening $\mathrm{CH}$ could not be excluded in the future study.

\section{Conclusion}

In summary, this study is the first report to evaluate the association between $\mathrm{CH}$ and the HCRTR2, ADH4 and CLOCK 
genes in Chinese Han population. The results suggest that the HCRTR2 (rs10498801, rs2653342,rs2653349, rs3122156, rs3800539, rs9357855), $A D H 4($ rs1126671、rs1800759) and CLOCK (rs1801260) are not genetic risk factors for $\mathrm{CH}$ in the Chinese Han population. However, haplotype analysis found H1-GTGGGG was linked to a reduced $\mathrm{CH}$ risk.

\section{Additional files}

Additional file 1: Table S1. The sequences of the primers in this study (DOCX $12 \mathrm{~kb})$

\section{Abbreviations}

ADH: Alcohol dehydrogenase; $\mathrm{CH}$ : Cluster headache; CLOCK: Circadian Locomotor Output Cycles Kaput; GPCRs: G-protein-coupled receptors; hypocretin, HCRTs: Hypothalamus gastrin-releasing peptides; SNPs: Single nucleotide polymorphisms

\section{Acknowledgements}

None

\section{Funding}

This work was supported by the National Natural Science Foundation of China. (Grants No. 81671077, No. 81471147).

\section{Availability of data and materials}

The data supporting their findings can be found in our manuscript.

\section{Authors' contributions}

ZF performed the experiments and draft the paper; LH, DW collected data and carried out statistical analyses; DZ and RA participated in statistical analyses and revised the manuscript; SY designed the study; All authors approved the final version of manuscript.

\section{Ethics approval and consent to participate}

The present study was approved by the Ethics Committees of the Chinese PLA General Hospital. Written informed consent was received from patients.

\section{Consent for publication}

Not applicable.

\section{Competing interests}

The authors declare that they have no competing interests.

\section{Publisher's Note}

Springer Nature remains neutral with regard to jurisdictional claims in published maps and institutional affiliations.

\section{Author details}

'Department of Neurology, Chinese People's Liberation Army General Hospital, Fuxing Road 28, Haidian District, Beijing 100853, China. ${ }^{2}$ The third department of Neurology, Affiliated Xingtai People's Hospital of Hebei Medical University, Xingtai, Hebei Province 054000, China.

Received: 10 November 2017 Accepted: 26 December 2017 Published online: 09 January 2018

\section{References}

1. Dong Z, Di H, Dai W, Pan M, Li Z, Liang J, Zhang M, Zhou Z, Liu R, Yu S (2013) Clinical profile of cluster headaches in China - a clinic-based study. J Headache Pain 14:27

2. Headache Classification Committee of the International Headache Society(IHS) (2013) The international classification of headache disorders, 3rdedition (beta version). Cephalalgia 33:629-808

3. Schurks M (2010) Genetics of cluster headache. Curr Pain Headache Rep 14:132-139

4. Taga A, Russo M, Manzoni GC, Torelli P (2015) Familial cluster headache in an Italian case series. Neurol Sci 36(Suppl 1):141-143
5. Russell MB, Andersson PG, Thomsen LL (1995) Familial occurrence of cluster headache. J Neurol Neurosurg Psychiatry 58:341-343

6. El Amrani M, Ducros A, Boulan P, Aidi S, Crassard I, Visy JM, TournierLasserve E, Bousser MG (2002) Familial cluster headache: a series of 186 index patients. Headache 42:974-977

7. Leone M, Russell MB, Rigamonti A, Attanasio A, Grazzi L, D'Amico D, Usai S, Bussone G (2001) Increased familial risk of cluster headache. Neurology 56:1233-1236

8. Couturier EG, Hering R, Steiner TJ (1991) The first report of cluster headache in identical twins. Neurology 41:761-761

9. Roberge C, Bouchard JP, Simard D, Gagne R (1992) Cluster headache in twins. Neurology 42:1255-1256

10. Sjaastad O, Shen JM, Stovner LJ, Elsas T (1993) Cluster headache in identical twins. Headache 33:214-217

11. Russell MB, Andersson PG, Thomsen LL, Iselius L (1995) Cluster headache is an autosomal dominantly inherited disorder in some families: a complex segregation analysis. J Med Genet 32:954-956

12. Leone M, Proietti Cecchini A (2017) Advances in the understanding of cluster headache. Expert Rev Neurother 17:165-172

13. Li SB, Jones JR, de Lecea L (2016) Hypocretins, neural systems, physiology, and psychiatric disorders. Curr Psychiatry Rep 18:1-12

14. Nixon JP, Mavanji V, Butterick TA, Billington CJ, Kotz CM, Teske JA (2015) Sleep disorders, obesity, and aging: the role of orexin. Ageing Res Rev 20:63-73

15. Weller CM, Wilbrink LA, Houwing-Duistermaat JJ, Koelewijn SC, Vijfhuizen LS, Haan J, Ferrari MD, Terwindt GM, van den Maagdenberg AM, de Vries B (2015) Cluster headache and the hypocretin receptor 2 reconsidered: a genetic association study and meta-analysis. Cephalalgia 35:741-747

16. Rainero I, Gallone S, Valfre W, Ferrero M, Angilella G, Rivoiro C, Rubino E, De Martino P, Savi L, Ferrone M, Pinessi L (2004) A polymorphism of the hypocretin receptor 2 gene is associated with cluster headache. Neurology 63:1286-1288

17. Schurks M, Kurth T, Geissler I, Tessmann G, Diener HC, Rosskopf D (2006) Cluster headache is associated with the G1246A polymorphism in the hypocretin receptor 2 gene. Neurology 66:1917-1919

18. Baumber L, Sjostrand C, Leone M, Harty H, Bussone G, Hillert J, Trembath RC, Russell MB (2006) A genome-wide scan and HCRTR2 candidate gene analysis in a European cluster headache cohort. Neurology 66:1888-1893

19. Rozen TD, Fishman RS (2012) Cluster headache in the United States of America: demographics, clinical characteristics, triggers, suicidality, and personal burden. Headache 52:99-113

20. Edenberg HJ (2000) Regulation of the mammalian alcohol dehydrogenase genes. Prog Nucleic Acid Res Mol Biol 64:295-341

21. Buervenich S, Sydow O, Carmine A, Zhang Z, Anvret M, Olson L (2000) Alcohol dehydrogenase alleles in Parkinson's disease. Mov Disord 15:813-818

22. Luo X, Kranzler HR, Zuo L, Yang BZ, Lappalainen J, Gelernter J (2005) ADH4 gene variation is associated with alcohol and drug dependence: results from family controlled and population-structured association studies. Pharmacogenet Genomics 15:755-768

23. Rainero I, Rubino E, Gallone S, Fenoglio P, Negro E, De Martino P, Savi L, Pinessi L (2010) Cluster headache is associated with the alcohol dehydrogenase 4 (ADH4) gene. Headache 50:92-98

24. Zarrilli F, Tomaiuolo R, Ceglia C, Lombardo B, Izzo B, Castaldo G, Pastore L, De Simone R (2015) Molecular analysis of cluster headache. Clin J Pain 31:52-57

25. Fourier C, Ran C, Steinberg A, Sjostrand C, Waldenlind E, Carmine Belin A (2016) Screening of two ADH4 variations in a Swedish cluster headache case-control material. Headache 56:835-840

26. Ofte HK, Tronvik E, Alstadhaug KB (2015) Lack of association between cluster headache and PER3 clock gene polymorphism. J Headache Pain 17:18

27. Rainero I, Rivoiro C, Gallone S, Valfre W, Ferrero M, Angilella G, Rubino E, De Martino P. Savi L, Lo Giudice R, Pinessi L (2005) Lack of association between the 3092 T->C clock gene polymorphism and cluster headache. Cephalalgia 25:1078-1081

28. Cevoli S, Mochi M, Pierangeli G, Zanigni S, Grimaldi D, Bonavina G, Torelli P, Manzoni GC, Cortelli P, Montagna P (2008) Investigation of the T3111C CLOCK gene polymorphism in cluster headache. J Neurol 255:299-300

29. Fourier C, Ran C, Zinnegger M, Johansson AS, Sjöstrand C, Waldenlind E, Steinberg A, Belin AC (2017) A genetic CLOCK variant associated with cluster headache causing increased mRNA levels. Cephalalgia. doi: https:// doi.org/10.1177/0333102417698709. [Epub ahead of print]

30. Eising E, Pelzer N, Vijfhuizen LS, Vries B, Ferrari MD, Hoen PA, Terwindt GM, van den Maagdenberg AM (2017) Identifying a gene expression signature of cluster headache in blood. Sci Rep 7:40218 